\title{
Designing and performance investigation of permanent magnet motor prototype for UTV electric drive train application
}

\author{
Muhammad Nur Yuniarto', Yoga Uta Nugraha², I Made Yulistya Negara ${ }^{3}$, \\ Dimas Anton Asfani ${ }^{4}$, Indra Sidharta ${ }^{5}$ \\ ${ }^{1,5}$ Department of Mechanical Engineering, Faculty of Industrial Technology and Systems Engineering, Institut Teknologi \\ Sepuluh Nopember, Surabaya, Indonesia \\ ${ }^{2-4}$ Department of Electrical Engineering, Faculty of Intelligent Electrical and Informatics Technology, Institut Teknologi \\ Sepuluh Nopember, Surabaya, Indonesia
}

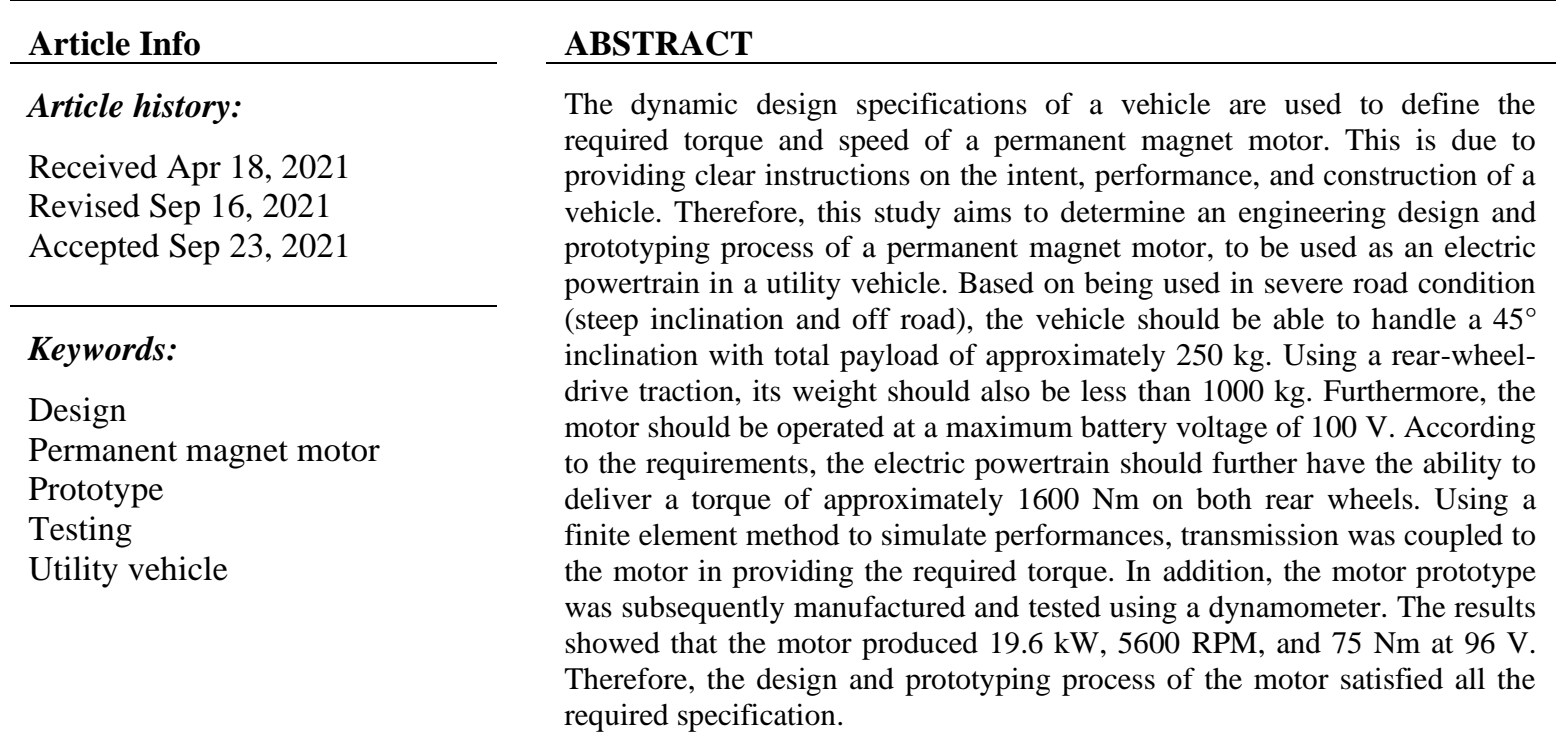

This is an open access article under the CC BY-SA license.

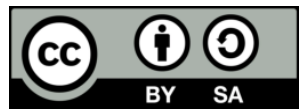

\section{Corresponding Author:}

Muhammad Nur Yuinarto

Department of Mechanical Engineering

Institut Teknologi Sepuluh Nopember

Keputih Sukolilo, Surabaya 60111, Indonesia

Email:mnur@me.its.ac.id

\section{INTRODUCTION}

Electrification in transportation modes has continuously increased in recent years, with electric vehicles offering several advantages based on the production of no fossil fuel, high efficiency and zero emissions. These advantages are significant for countries where fossil fuel supply is scarce, such as Indonesia. This indicates that there are some areas lacking good road facilities with no availability of fossil fuel in the country. These areas often use utility vehicles for transporting people or goods. However, their activities are always limited due to consistent lack of fuel supply. Based on this condition, the technology of electric vehicles emphasize the possibility of better transportation medium for these areas. As reported by [1], the media used in these areas are known as electric utility vehicles (UTV). This is due to the UTV being the best form of utilized alternative these disadvantaged and challenging regions [2], [3]. It helps in the conservation of energy because of the inherent high efficiency in electric vehicles. Another study also made 
reports on the hybrid system of sports' electric UTV [4]. In addition, the electric utility vehicle has the ability to be used for basic freight transportation within closed areas and military applications [5], [6].

Several traction technologies are further used in the electric UTV, i.e., induction motors are popularly utilized in the Tesla S vehicle Models. Meanwhile, rotor cooling is a challenge for the application of these designs in electric vehicles [7]. Based on having instant torque characteristics, the DC motors are widely used at the beginning of electric vehicle technologies. However, this is gradually being replaced with Brushless DC motor technologies, due to the necessity of brush replacement as a commutation component [8]. The structure in these brushless designs use permanent magnets on the side of the rotor. The development of control technology ensures the wider improvement of permanent magnet motors, to obtain better performance and efficiency [9]. According to Kim et al. and Vakil, the type of technology suitable for the UTV power train was the permanent magnet motor [1], [10].

This study aims to analyze the design of permanent magnet motors for the operations of utility electric vehicles. Several design considerations involve the general characteristics of UTV, such as high torque, durability, lightweight-compact chassis, great water index protection, and dust ingress. Also, being powerful and capable is the key for all activities [11], [12]. In the design process, the value of torque, speed, maximum weight, and other several parameters are considered towards accommodating the engine characteristics needed by the vehicles.

The main contribution of this study is to consider all mechanical and electrical aspects in the design process. In addition, detailed procedural calculations are also being presented for analytical utilization. The process design and electric traction prototyping are based on the vehicular dynamic data obtained from the existing UTV in Indonesia. According to these data, the required torque, power, and speed for the electric traction motor are further calculated and determined. Using finite element methods, several simulation and modeling are employed to design the proposed UTV components. This method further helped in estimating the performances and characteristics of the proposed electric traction motor. Using the simulation data, the electric design is reportedly manufactured. To evaluate the prototype performances of the electric motor per simulation, an experiment is further conducted, where all characteristics are vehemently recorded. In addition, the results are also compared with the those from the simulation and modeling outputs.

The study is further organized as shown in sections 2 and 3, which explains the design specifications and engineering processes of the UTV's electric traction motor, respectively. Furthermore, section 4 explains the simulations of the electric motor and its temperature distribution, to determine performances and cooling methods, respectively. In addition, sections 5 and 6 presents the motor's performance analysis and the discussion of the study, respectively.

\section{PERMANENT MAGNET DESIGN SPECIFICATION}

The static and dynamic parameters of a vehicle should be determined and considered when accurately designing a permanent magnet electric motor. These static elements were based on the existing Fin Komodo UTV in Figure 1, as shown in Table 1. Based on the requirement, the UTV should have the capability of handling all road terrains at a maximum inclination of $45^{\circ}$, with a payload of approximately 250 $\mathrm{kg}$. Meanwhile, an analytical calculation was carried out according to the dynamic requirements of the vehicle, as shown in Table 2.

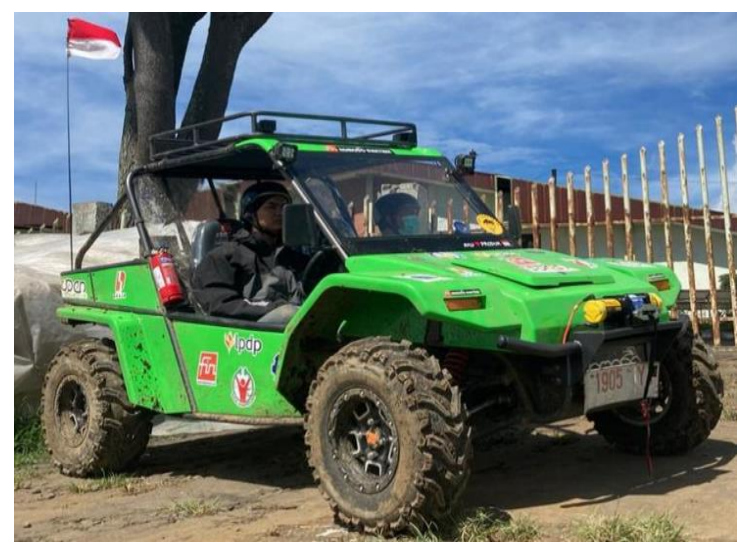

Figure 1. Existing UTV Fin Komodo 
Table 1. UTV static parameters

\begin{tabular}{lll}
\hline \multicolumn{1}{c}{ Parameters } & \multicolumn{1}{c}{ Value } & Unit \\
\hline Frontal area & 1 & $\mathrm{~m}^{2}$ \\
Vehicle mass & 800 & $\mathrm{Kg}$ \\
Tire rolling resistance coefficient & 0,01 & \\
Brake and Steering Resistance & 1 & \\
Drag Coefficient & 0,08 & \\
Air Density & 1,2 & $\mathrm{~kg} / \mathrm{m}^{3}$ \\
\hline
\end{tabular}

Table 2. UTV dynamic parameters

\begin{tabular}{lll}
\hline Requirement & Value & Unit \\
\hline Power & 20 & $\mathrm{~kW}$ \\
Torque & 80 & $\mathrm{Nm}$ \\
Speed & 6000 & $\mathrm{RPM}$ \\
Voltage & 96 & $\mathrm{~V}$ \\
Max Current Phase & 600 & $\mathrm{~A}$ \\
Low gear drive ratio & $1: 30$ & \\
High gear drive ratio & $1: 16$ & \\
Crawling speed & 10 & $\mathrm{KPH}$ \\
Maximum speed & 40 & $\mathrm{KPH}$ \\
\hline
\end{tabular}

Based on these descriptions, the electric powertrain was installed in an existing UTV, with the important consideration of available vehicular space, whose measurement produced $400 \mathrm{~mm}$ each on length, width, and height. The dimensions of the motor were defined by these data, as transmission was stated not to exceed those volumes. According to the consequences of using several motors in this application, the best suitable design was selected to meet the requirements of the electric UTV. Also, the determination of several criteria was conducted in the selection process. For this application, the highest efficiency, best power density, and wide speed range, should be easily maintained. Furthermore, the torque characteristics of the motor are very important. This indicates that greater torque is highly preferable for production, as the electric UTV is to be operated in various road conditions and steep inclinations [10]. Hashemnia and Asei studied several electric motor technologies [8], with the results shown in Tables 3 and 4. Based on these illustrations, the induction motor was the best performer, and its application was used for the traction motor of General Electric (road) Vehicles. For off-road applications, two performance characteristics and their comparative results were further added, as shown in Table 4.

Table 3. Comparative study of various electric motor technology [8]

\begin{tabular}{lcccc}
\hline \multicolumn{1}{c}{ Characteristic } & $\begin{array}{c}\text { Direct Current } \\
\text { (DC) }\end{array}$ & $\begin{array}{c}\text { Propulsion Systems } \\
\text { (IM) }\end{array}$ & $\begin{array}{c}\text { Permanent Magnet } \\
\text { (PM) }\end{array}$ & $\begin{array}{c}\text { Switch Reluctance Motor } \\
\text { (SRM) }\end{array}$ \\
\hline Power Density & 2.5 & 3.5 & 5 & 3.5 \\
Efficiency & 2.5 & 3.5 & 5 & 3.5 \\
Controllability & 5 & 5 & 4 & 3 \\
Reliability & 3 & 5 & 4 & 5 \\
Technological Maturity & 5 & 5 & 4 & 4 \\
Cost & 4 & 5 & 25 & 4 \\
$\Sigma$ Total & 22 & 27 & & 23 \\
\hline
\end{tabular}

A similar score to the study of [8] was also used for each characteristic. The two additional characteristics implemented during the off-road applications were the low RPM torque and installation complexity. Based on Table 4, the PM motor was the best applicable design for the off-road process. Meanwhile, the induction motor (IM) was the best design for on-road application according to Goto et al. [13]. Also, the manufacture and installation complexity was not considered as a characteristic factor [9], [14]. The IM further required a special rotor cooling technique to improve its reliability. When this technique is not applied, the reliability of the motor significantly decreases due to overheating, leading to the proneness to failure [13], [15]-[17]. Additional cooling also increases the production and complexity of the IM, based on the requirement of a special rotor design. In addition, installation complexity increases due to a freezing route around the IM, which should be separated between rotor and stator cooling. Several electric vehicles using IM as powertrain includes Tesla model S, as well as Honda Fit and Toyota RAV4 EV [8]. These vehicles also used special technique to cool the rotor and stator of the IM. 
Table 4. Comparison of various electric motor technologies for off-road application [8]

\begin{tabular}{lcccc}
\hline \multicolumn{1}{c}{ Performance Characteristics } & DC Motor & IM & PM & SRM \\
\hline Power Density & 2.5 & 3.5 & 5 & 3.5 \\
Efficiency & 2.5 & 3.5 & 5 & 3.5 \\
Controllability & 5 & 5 & 5 & 3 \\
Reliability & 3 & 5 & 4 & 5 \\
Tech. Maturity & 5 & 5 & 4 & 3 \\
Cost & 4 & 5 & 3 & 5 \\
Torque at low RPM & 3 & 3 & 5 & 2.5 \\
Complexity of manufacturing and installation & 5 & 2 & 4 & 5 \\
Total Score & 30 & 32 & 35 & 31,5 \\
\hline
\end{tabular}

Based on Table 4, the Switched Reluctance Motor (SRM) was the third option for the traction of electric UTV. This offered advantages in terms of design and production simplicity. It also required no rotor magnetism or electromagnetism, as its production cost was the lowest among all types of traction motors. The disadvantages of the SRM were the lower power and torque density, which led to its unsuitability for off road application. However, the torque and power density on axial SRM are likely to be improved by the addition of several low-cost permanent magnet [13], [15], [18]. This showed several promising results, although the improvements of the power and torque density were still lower than PM [19]. Furthermore, the DC Motor (permanent magnet and series-wound configuration) was the last option for the off-road application of e-UTV. This was because the design had the lowest efficiency due to the requirement of brush, which further ensured less reliability of the DC motor. The power and torque densities of the design were also the lowest, compared to other motor technologies.

The first choice for traction technology was the permanent magnet synchronous motor (PMSM), which was coincidentally the most popular in General Electric vehicle. This was due to its superiority to other motors, in terms of high efficiency (over 90\%), as well as power and torque densities. Therefore, the permanent magnet synchronous motor is more suitable for all types of electric vehicle applications, including off-road e-UTV. Unlike the DC motor, this design does not require a brush, leading to the reduction of maintenance cost, as well as increased reliability and robustness. Also, it does not require a special cooling system on its rotor. Several rotors in PMSM often contains neodymium permanent magnets, which are the strongest available elements that subsequently ensures the achievement of higher torque, compared to other electric motors. The torque generation of this design is special, due to being highly available for utilization at low RPM. Based on these descriptions, the PMSM was selected for utilization in the electric UTV. To further improve efficiency and performance, an interior V-shaped magnetic rotor was used as suggested by Miller [20], based on its high efficiency, wide range speed, and lower torque ripple. In addition, the PMSM showed be able to meet the design specification required for e-UTV application.

\section{DESIGN OF PERMANENT MAGNET MOTOR}

Based on the previous section, the first step of designing traction electric motor should be carried out by considering the static and dynamic parameters of e-UTV. Detailed design should also ensure that all parameters and specification requirements are met by the PMSM. When designing an electric motor, the first step is to determine its basic idea. According to Miller and Xie et al., the topology of the PMSM was an interior V-type magnetic rotor [20], [21], as determined and shown in Table 5.

According to Miller [22], the first parameters to determine were its electric (A) and magnetic (B) loadings, as well as the torque per rotor value (TRV). The collection of these parameters was used to determine the detailed data in the winding area, including the turns on each stator, as well as diameter size and total length of the copper wire. The electric loading of the PMSM is calculated in (1),

$$
A=\frac{2 m N_{p h} I_{p h}}{\pi D}
$$

where

$m$ : number of phases

$N_{p h}:$ number of windings turns

$I_{p h}:$ the motor root means square current

D : the motor outer diameter shown in (2),

Once A is defined, the second parameter to be calculated is the PMSM magnetic loading (B), as 
$B=\frac{2 p \phi_{1}}{\pi D L_{s t k}}$

where

$L_{s t k}:$ the total length of PMSM stator,

$D \quad$ : rotor outer diameter

$\phi_{1}$ : the motor flux linkage over a specific air gap, and

$p \quad$ : the number of motor pole pairs.

Furthermore, the motor electro motive force (EMF) on each phase is calculated using (3),

$$
E=\frac{2 \pi}{\sqrt{2}} k_{w 1} N_{p h} \phi_{1} f
$$

where,

$f \quad$ : the motor electrical frequency

$k_{w 1}$ : the motor harmonic winding factor

with values often between 0.8 and 1 . To determine the PMSM dimensions, the values of motor winding correlating with TRV in each phase $N_{p h}$ were further estimated, as shown in the Table 6.

Table 5. Basic design of the PMSM

\begin{tabular}{ll}
\hline \multicolumn{1}{c}{ Motor Type } & Permanent Magnet Motor \\
\hline Rotor Type & V type interior \\
Number of Phases & 3 phases \\
Stator/rotor poles & $12 / 8$ poles \\
Winding Configuration & Concentrated \\
Permanent Magnet & N42H \\
Electromagnetic steel plates & $35 \mathrm{~W} 300$ \\
\hline
\end{tabular}

Table 6. Typical value of TRV [20]

\begin{tabular}{lc}
\hline \multicolumn{1}{c}{ Class of machine } & TRV $\left(\mathrm{kNm} / \mathrm{m}^{3)}\right.$ \\
\hline Small totally-enclosed motor (Ferrite magnets) & $7-14$ \\
Totally-enclosed motor (sintered rare earth or & $14-20$ \\
NdFeb) & \\
Integral-hp industrial motors & $7-30$ \\
High-performance servomotors & $15-50$ \\
Aerospace machine & $30-75$ \\
\hline
\end{tabular}

Based on Table 6, the TRV value of the PMSM was $14-20(\mathrm{kNm} / \mathrm{m} 3)$. This was because the designed PMSM used Neodymium magnet (NdFeb), and was a totally-enclosed motor. The value of $\mathrm{A}$ and $\mathrm{B}$ for this motor is determined by,

$$
T R V=\frac{T}{V_{r}}=\frac{\pi}{\sqrt{2}} k_{w 1} A B
$$

The number of winding $\left(N_{p h}\right)$ on each PMSM phase was subsequently estimated using equation (1), and shown as follows,

$$
N_{p h}=\frac{A \pi D_{r}}{2 m I_{p h}}
$$

Based on (1) to (5), the basic parameters of the PMSM are recapitulated in Table 7. As the basic design parameters were determined, the next step was to draw the physical shape of the PMSM and evaluate its mechanical dimensions. This is explained below, as the typical rotor and stator dimensions of the design are presented in Figure 2. According to Figure 2, there are several dimensions of the PMSM that should be defined, calculated, and determined. This was the first iteration in terms of defining the mechanical dimensions of the PMSM. Based on the FEM simulation, the final mechanical dimensions of the design was determined. Furthermore, the mechanical dimensions of the stator were $r_{r}, R_{r a}, R_{r a d}$, and $R_{\text {radbk }}$, respectively. To determine these values, the split ratios of 0.55 to 0.65 were utilized. This indicated that the PMSM had similar split ratio than the AC induction motor [21]. $R_{\text {radbk }}$ was defined based on the constraint 
that the maximum diameter of the PMSM was unable to exceed higher available space in the e-UTV power train area. Therefore, the determination of this value led to the definition of the remaining dimensions. To determine back iron depth $\left(d_{b k}\right)$, the following formula was used. Where, $N_{s l}=$ number of slots, $m=$ number of phases, $t_{w}=$ slot tooth width, $N_{p}=$ number of poles.

$$
d_{b k}=\frac{N_{s l} m}{N_{p}} t_{w}
$$

The next step after this design determination was to estimate the resistance $\left(R_{S}\right) . R_{S}$ was estimated based on the stator cross-sectional area (CSA) and total length of enameled wire. The following equations were used to estimate the stator CSA and $R_{S}$.

$$
\begin{aligned}
& A_{\text {slots }}=\pi\left(r_{\text {rad }}^{2}-r_{\text {ra }}^{2}\right)-N_{s l} d t_{w} \\
& A_{c u(\text { total })}=F_{\text {slots }} A_{\text {slots }} \\
& A_{c u(\text { wire })}=A_{c u(\text { total })} /\left(6 N_{p h}\right) \\
& d_{c u(\text { wire })}=2 \sqrt{A_{\text {cu(wire })} / \pi} \\
& d_{\text {wire }}=\frac{d_{c u(\text { wire })}}{2} \sqrt{\frac{\pi}{F_{\text {slot }}}} \\
& l_{p h}=N_{p h}\left(l_{\text {end }}+L_{s t k}\right) \\
& R_{s}=\left(\frac{l_{p h}}{\sigma_{c u} A_{c u(\text { wire })}}\right)
\end{aligned}
$$

Table 7. Basic design of the PMSM

\begin{tabular}{ccc}
\hline Basic Parameter & Value & Units \\
\hline$A$ & 63,69 & - \\
$B$ & 0,0069 & - \\
$T R V$ & $14-20$ & $\mathrm{kNm} / \mathrm{m}^{3}$ \\
$N_{p h}$ & 4 & turn \\
$k_{w 1}$ & $0,85-0,95$ & - \\
$L_{s t k}$ & 80 & $\mathrm{~mm}$ \\
$D$ & 180 & $\mathrm{~mm}$ \\
$\phi_{1}$ & 39 & - \\
$f$ & 20 & $\mathrm{kHz}$ \\
\hline
\end{tabular}

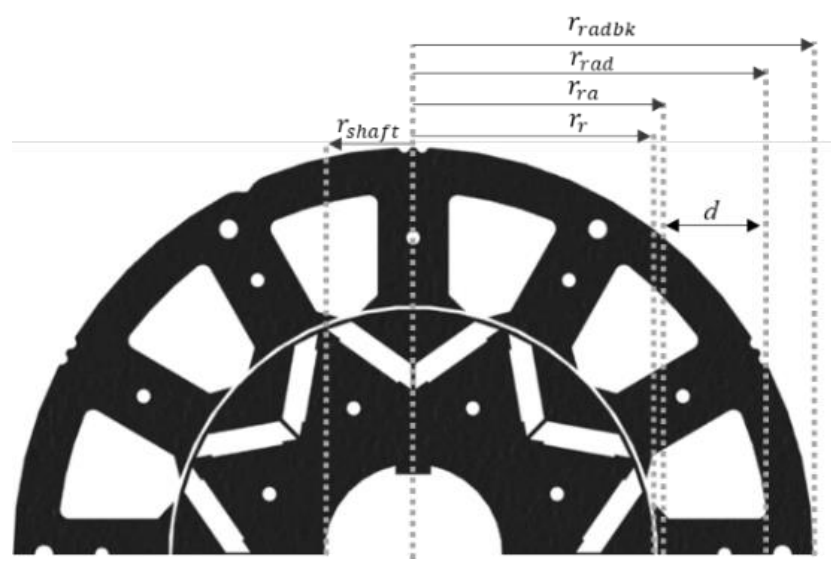

Figure 2. Illustration of the typical PMSM stator and rotor 
As shown in (6) to (13), the value of the motor's mechanical dimensions was solved, with the stator and rotor poles at 12 and 4 pairs, respectively. Each rotor pole used two interior V-shaped magnets, which were selected due to the reduction of high rotation risk, such as the eradication of magnets. In addition, the magnetization was more evenly distributed for the reduction of cogging. When the cogging torque was minimized, the PMSM had smoother rotation, leading to higher efficiency [23]-[26]. The rotor and stator should also contain laminated silicon steel sheets, which are bonded through the insertion of pegs as locking mechanism.

Based on the design processes, the complete CAD drawing of the initial PMSM stator and rotor are shown in Figure 3. This drawing was subsequently used in the FEM software, to simulate the expected performance of the PMSM. On the left and right sides of the illustration are the stator and rotor, respectively. The detailed size described and evaluated in this simulation includes air gap check, as well as the manufacturing possibility for radius and winding slots.
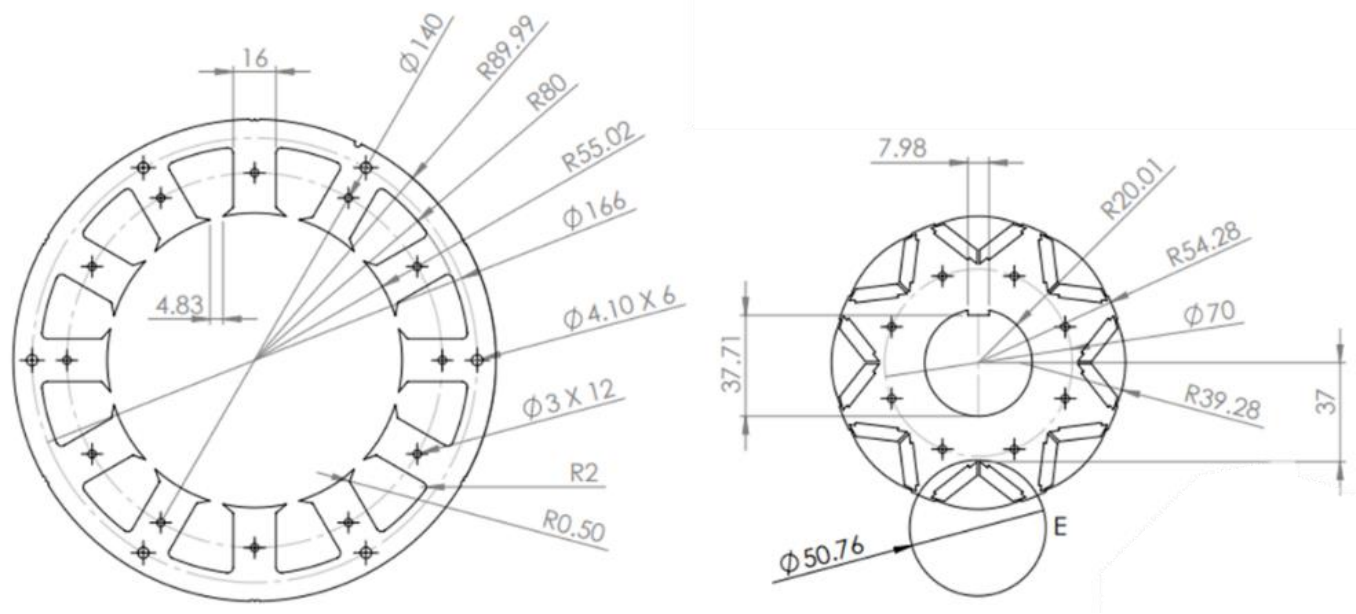

Figure 3. Initial PMSM rotor and stator CAD drawing

\section{PMSM SIMULATION MODEL DEVELOPMENT}

A detailed explanation on the FEM simulation of PMSM was presented in this section. Based on Table 4, the PMSM mechanical model was initially developed to simulate the estimated performance. The model contained PMSM stator, rotor, and magnet. The red, dark-green, and green colors represented the stator, permanent magnet, and rotor, respectively. Also, the wounded wire in the stator slot was represented by the yellow color.

Based on the input required by the FEM software, the PMSM model was supplied with several data. The maximum dimension of this model was also selected to accurately fit the available space within the UTV powertrain area. This indicated that the outer diameters of the stator and rotor were 180 and $108 \mathrm{~mm}$, respectively. Moreover, the NdFeb magnets with thickness of $5 \mathrm{~mm}$ was further used in the simulation. As previously explained, the number of magnets were 16, with 4 pole pairs. The complete list of mechanical parameters used in this simulation is shown in Table 8.

Based on the basic design and calculation of the PMSM parameters in Table 9, 12 windings were observed, with each phase containing 4 constituents. These phases are further known as U, V, and W stages, respectively. According to the length of wire using (12), 5 turns were observed on each phase. Two parallel paths of winding were also used to obtain rotational speed in each phase. This winding model is further shown in Figure 4. Also, the modeled and simulated PMSM had concentrated winding configuration. Based on the simulation process, the design had a fill factor of $58 \%$ with the concentrated winding, due to the wire being manually winded. In addition, several parameters within the simulation process were the constraint factors used to conduct and estimate PMSM performance, as shown in Table 9. 


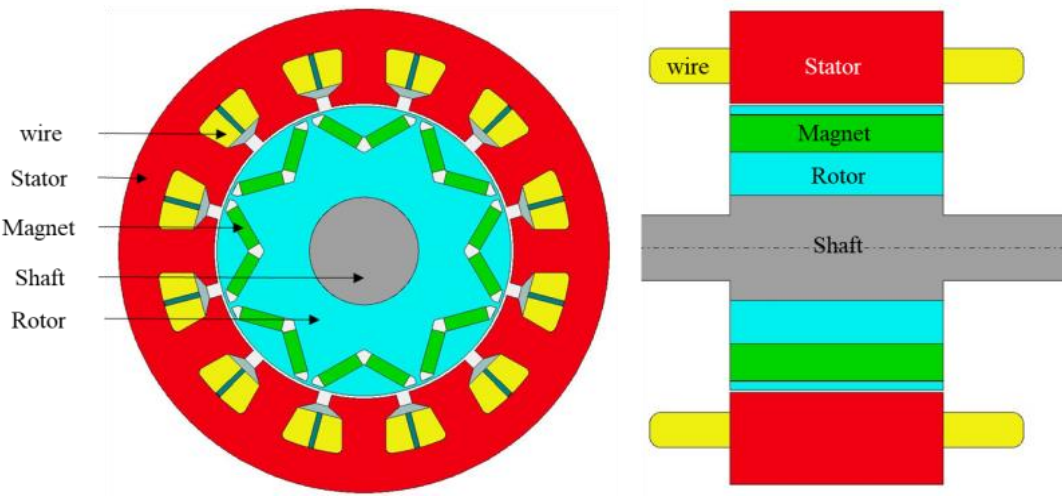

Figure 4. Mechanical model of PMSM

Table 8. Parameters of the mechanical model used in the simulation

\begin{tabular}{cr}
\hline Parameter & \multicolumn{1}{c}{ Value } \\
\hline Stator Outer Diameter & $180 \mathrm{~mm}$ \\
Stator Inner Diameter & $90 \mathrm{~mm}$ \\
Tooth width & $15.9 \mathrm{~mm}$ \\
Tooth depth & $22 \mathrm{~mm}$ \\
Stack length & $90 \mathrm{~mm}$ \\
Magnet Thickness & $5 \mathrm{~mm}$ \\
Magnet Width & $90 \mathrm{~mm}$ \\
Magnet angle & $43^{\circ}$ \\
\hline
\end{tabular}

Table 9. Parameters of the mechanical model used in the simulation

\begin{tabular}{lll}
\hline \multicolumn{1}{c}{ Parameter } & \multicolumn{1}{c}{ Value } & Unit \\
\hline Shaft speed & 6000 & RPM \\
Peak Current & 550 & A \\
RMS Current & 388.9 & A \\
DC bus Voltage & 100 & V \\
Phase (Elec Deg) & 45 & $\circ$ \\
Drive Mode & Sine & \\
Winding Connection & Star Connection & \\
Magnetization & Radial & \\
Skew & None & \\
& &
\end{tabular}

The second step of the simulation was to estimate the electromagnetic performance of the PMSM. This was carried out through the development of a magnetic loading model, as shown in Figure 5. Once defined, the electromagnetic simulation was immediately performed. Based on the simulation, the designed motor had magnetic flux linkage, output, maximum speed, and torque of $38.9 \mathrm{mVs}, 20.2 \mathrm{KW}$, $6000 \mathrm{RPM}$, and $75 \mathrm{Nm}$, respectively. According to these results, the PMSM model produced is found to be correct. After this, the next step was to prototype the PMSM and test it through a dynamometer bench. This was to confirm the performance accuracy of the motor, as stated by the mathematical calculation and simulation.

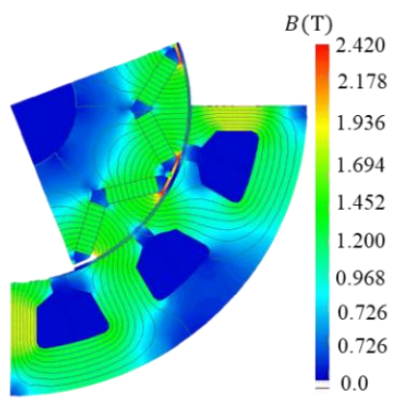

Figure 5. Stator and rotor magnetization flux

\section{PROTOTYPING}

Based on the simulation, the prototype of the PMSM was manufactured, with the red component indicating the motor casing, whose main function is to support the whole elements as one structural integrity units. However, separate analysis of the material strength and dimensions were performed and reported in other studies. Based on the UTV application requirements, the PMSM should be waterproof, and also meet the IP68 standard. Special seals and other sources of waterproofing techniques were utilized in the casing system, to ensure the total protection of the PMSM from water and dust ingress. The material selected for this process was the aluminum 6061. Based on the thermal analysis, this material had superior performance in

Designing and performance investigation of permanent magnet motor ... (Muhammad Nur Yuniarto) 
terms of heat dissipation from the stator. The cooling system and its thermal performance in this motor was also designed and studied. Based on this condition, the most optimum results obtained using water as coolant, showed that the jacket (water channel) was inside the perimeter of the PMSM casing. In addition, the complete final design of this motor is shown in Figure 6.

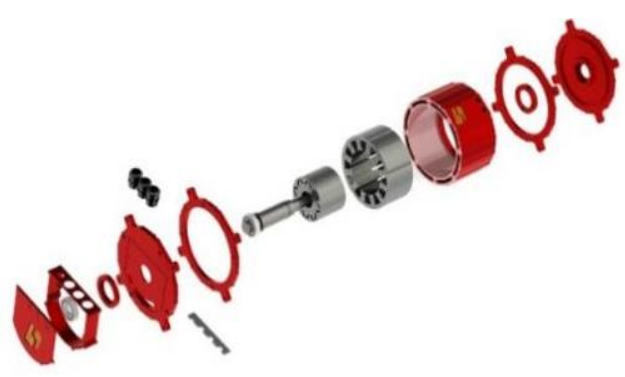

Figure 6. 3D exploded view of the PMSM

The prototype was manufactured for the validation of calculations and simulations. This indicated that the manufacturing activities were conducted through casing, permanent magnets, and stator-rotor part productions, respectively. The stator was provided with an insulation layer, to keep the enameled wire from scratches during the winding process. Liquid insulation was further added in this process (winding), to maintain the quality on the winding during the assembly phase.

The installation of magnets on the rotor slots should also consider the unbalanced possibility of the PMSM rotor. This is because the model was operated at high RPM (6000 RPM), causing excessive vibration. To anticipate this problem, the weighing on each magnet should be conducted and installed according to the appropriate weight distribution. In addition, a cover or high temperature epoxy glue was needed on the outer side of the rotor, to keep the magnets from being thrown off. Once all the magnetic installation is complete, rotor balancing is further required.

The stator was assembled inside the perimeter of the main casing part, where a special dissipation pad was used to ensure good heat transfer from the stator. As previously stated, the round rubber seal on the area of casing surface was used to maintain waterproofing. A special sealing method was also utilized on the surfaces (two sides) of the main casing (left and right covers). Furthermore, the complete assembly process of the PMSM prototype is shown in Figure 7. To determine the realistic performance of the motor, a test was carried out using a dynamometer. The experimental configuration to torque, speed, and power of the PMSM prototype is also shown in Figure 8. To test this prototype, the Eddy current dynamometer with preprogrammed load was used.

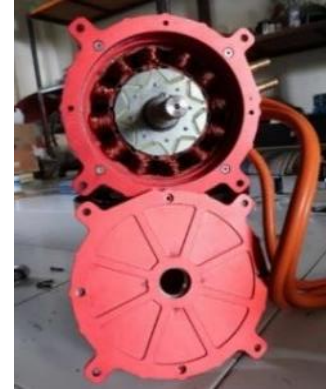

Figure 7. Assembly of electric motor prototype

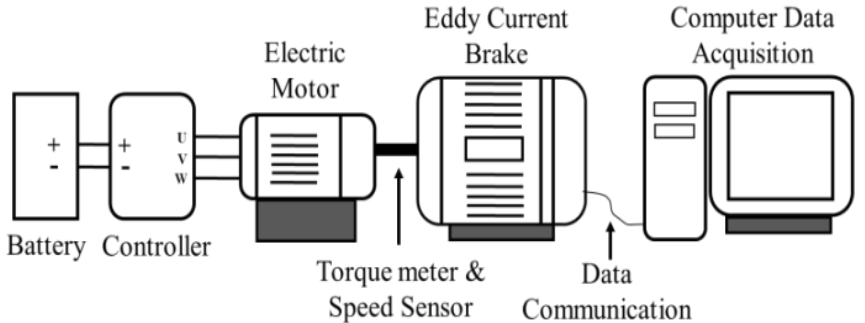

Figure 8. Experimental set up of PMSM performance measurement

Based on Figure 8, the experiment used $100 \mathrm{~V}$ and 100 Ah battery packs. The PMSM controller was used to control the speed and torque, according to the preprogrammed dynamometer load. The acquisition of the dynamometer data was also used to record the motor's performance (torque and speed). Moreover, the dynamometer software reported all necessary graphs, i.e., torque vs velocity and power vs speed, 
respectively. Figure 9 showed that the prototype of the PMSM had maximum power, as well as stall torque and speed of $19.6 \mathrm{~kW}, 75 \mathrm{Nm}$, and $5600 \mathrm{RPM}$, respectively.

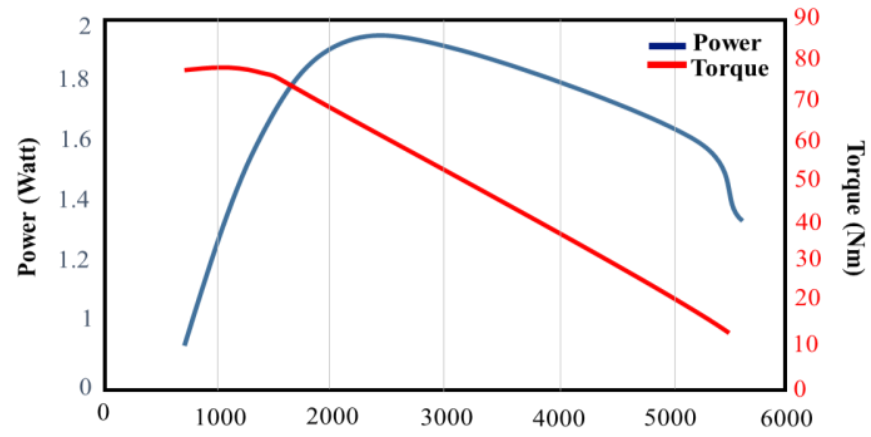

Figure 9. Performance test result

\section{DISCUSSION}

This study described the electrical and mechanical design processes of an electric motor, through the application of a permanent magnet on a utility vehicle (UTV). By considering the specifications of the UTV (weight, speed, and maximum terrain inclination of $45^{\circ}$ ), the design and prototype of a PMSM was conducted as an electric drivetrain. Based on the engineering process and simulation, the PMSM prototype had power, torque, and speed of $20 \mathrm{~kW}, 80 \mathrm{Nm}$, and $6000 \mathrm{RPM}$, respectively. Moreover, a permanent interior $\mathrm{V}$-shaped magnetic motor was selected for this process. From the design specifications, the detailed dimensions of the stator and rotor was further obtained in the electric motor. In addition, the turns and size specifications of the enameled wire were obtained.

The designed PMSM was manufactured and tested using a dynamometer, with several analysis and experiments further performed to obtain the motor's characteristics. To validate the prototype accuracy, the comparison of performances was conducted, as shown in Figure 10.

Based on Figure 10, the tests and experiments were confirmed with expected performance parameter of the PMSM. The difference in the torque generated was only $8.5 \%$ smaller than the simulation. The power generated through the simulation was also $3.9 \%$ higher than the prototype. The full comparisons are presented in Table 10. The comparative values obtained were acceptable, indicating that the PMSM prototype was performing effectively during the tests and experiments.

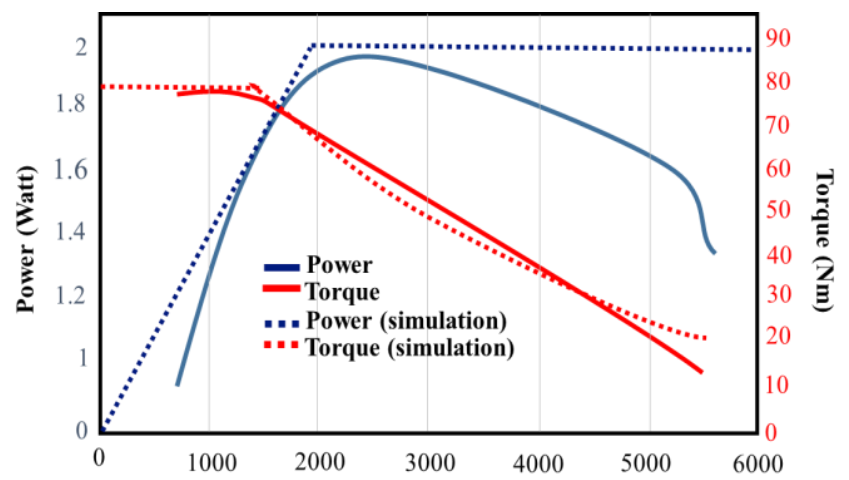

Figure 10. Performance test comparison

Table 10. Performance comparison between simulation and prototype

\begin{tabular}{cccc}
\hline Parameter & Simulation & Prototype & Comparison \\
\hline Power (W) & 20.2 & 19.6 & $-2.9 \%$ \\
Torque (Nm) & 75 & 82 & $+9 \%$ \\
Shaft speed (RPM) & 6000 & 5600 & $-7 \%$ \\
\hline
\end{tabular}


The highest torque obtained from the test was $82 \mathrm{Nm}$, which decreased when the rotor speed was 1500 RPM. The same pattern was observed from the test results, although the highest torque obtained was 75 $\mathrm{Nm}$, which decreased when the speed was 1300 RPM. Meanwhile, there was a significant difference in torque values when the speed was 2000 RPM. This was due to the test conditions in the dynamometer, which had a minimum rotation limit for data collection. Therefore, data recording began from 800 RPM to the maximum speed of the motor. In the power graph, the test showed a value of $850 \mathrm{~W}$ at the initial point of data collection, which was slightly larger than the simulation at $750 \mathrm{~W}$. At a speed of $1500 \mathrm{RPM}, 17,000 \mathrm{~W}$ was obtained, with the peak value observed at 2500 RPM.

\section{CONCLUSION}

This study reported the design process of a PMSM using dynamometer, as the derived formulas were used as a guide for constructing electric motors. The finite element method was also used to validate the design and determine the core parameters, such as power, torque, and speed. Furthermore, the prototype was tested through a dynamometer, to determine and compare the performances, as well as simulation results. The size of the stator, rotor, and winding pattern are used as a reference for further studies, which should involve the realistic performances of the complete design process. This test should be crucial to this study, based on judging the effectiveness and efficiency of the designed PMSM against the challenges posed by the realistic application of the electric UTV.

\section{ACKNOWLEDGEMENTS}

The author is grateful to the Lembaga Pengelola Dana Pendidikan (LPDP), for its support and funding of this study through the contract number of PRJ-5/LPDP/2020.

\section{REFERENCES}

[1] K. Kim, J. Lee, H. J. Kim, and D. Koo, "Multiobjective Optimal Design for Interior Permanent Magnet Synchronous Motor," IEEE Transactions on Magnetics, vol. 45, no. 3, pp. 1780-1783, March 2009, doi: 10.1109/TMAG.2009.2012820.

[2] R. Nagaraj, "Renewable energy based small hybrid power system for desalination applications in remote locations," 2012 IEEE 5th India International Conference on Power Electronics (IICPE), 2012, pp. 1-5, doi: 10.1109/IICPE.2012.6450437.

[3] F. Vellucci, G. Pede, M. Ceraolo, and T. Huria, "Electrification of Off-Road Vehicles: Examining the Feasibility for the Italian Market," World Electric Vehicle Journal, vol. 5, no. 1, no. 1, pp. 101-117, 2012, doi: 10.3390/wevj5010101.

[4] J. M. Tyrus, R. M. Long, M. Kramskaya, Y. Fertman, and A. Emadi, "Hybrid electric sport utility vehicles," in IEEE Transactions on Vehicular Technology, vol. 53, no. 5, pp. 1607-1622, Sept. 2004, doi: 10.1109/TVT.2004.832418.

[5] C. R. Durkin, C. D. Campos-Martinez, C. Y. Lee, and W. S. Vaz, "Design and Fabrication of an Electric Basic Utility Vehicle," 2020 IEEE International Conference on Electro Information Technology (EIT), 2020, pp. 211215, doi: 10.1109/EIT48999.2020.9208283.

[6] G. Khalil, "Challenges of hybrid electric vehicles for military applications," 2009 IEEE Vehicle Power and Propulsion Conference, 2009, pp. 1-3, doi: 10.1109/VPPC.2009.5289878.

[7] G. Sieklucki, "An Investigation into the Induction Motor of Tesla Model S Vehicle," 2018 International Symposium on Electrical Machines (SME), 2018, pp. 1-6, doi: 10.1109/ISEM.2018.8442648.

[8] N. Hashemnia and B. Asaei, "Comparative study of using different electric motors in the electric vehicles," 2008 18th International Conference on Electrical Machines, 2008, pp. 1-5, doi: 10.1109/ICELMACH.2008.4800157.

[9] R. M. Pindoriya, B. S. Rajpurohit, R. Kumar, and K. N. Srivastava, "Comparative analysis of permanent magnet motors and switched reluctance motors capabilities for electric and hybrid electric vehicles," 2018 IEEMA Engineer Infinite Conference (eTechNxT), 2018, pp. 1-5, doi: 10.1109/ETECHNXT.2018.8385282.

[10] G. I. Vakil and K. R. Rajagopal, "Performance comparison of sinusoidally-fed PM BLDC motors having different rotor topologies," 2010 Joint International Conference on Power Electronics, Drives and Energy Systems \& 2010 Power India, 2010, pp. 1-5, doi: 10.1109/PEDES.2010.5712565.

[11] Ranger, "Ranger EV," [Online]. Available: https://ranger.polaris.com/en-us/ranger-ev/.

[12] H. Goto, T. Shibamoto, K. Nakamura, and O. Ichinokura, "Development of high torque density axial-gap switched reluctance motor for in-wheel direct-drive EV," 2013 15th European Conference on Power Electronics and Applications (EPE), Sep. 2013, pp. 1-7. doi: 10.1109/EPE.2013.6634413.

[13] H. Goto, T. Shibamoto, K. Nakamura, and O. Ichinokura, "Development of high torque density axial-gap switched reluctance motor for in-wheel direct-drive EV," 2013 15th European Conference on Power Electronics and Applications (EPE), 2013, pp. 1-7, doi: 10.1109/EPE.2013.6634413. 
[14] Z. Yang, F. Shang, I. P. Brown, and M. Krishnamurthy, "Comparative Study of Interior Permanent Magnet, Induction, and Switched Reluctance Motor Drives for EV and HEV Applications," IEEE Transactions on Transportation Electrification, vol. 1, no. 3, pp. 245-254, Oct. 2015, doi: 10.1109/TTE.2015.2470092.

[15] P. Andrada, E. Martínez, M. Torrent, B. Blanqué, and J. I. Perat, "Novel in-wheel axial-flux segmented switched reluctance motor," 2017 19th European Conference on Power Electronics and Applications (EPE'17 ECCE Europe), 2017, pp. P.1-P.8, doi: 10.23919/EPE17ECCEEurope.2017.8099287.

[16] M. Popescu, N. Riviere, G. Volpe, M. Villani, G. Fabri, and L. di Leonardo, "A Copper Rotor Induction Motor Solution for Electrical Vehicles Traction System," 2019 IEEE Energy Conversion Congress and Exposition (ECCE), 2019, pp. 3924-3930, doi: 10.1109/ECCE.2019.8912248.

[17] B. Assaad, K. Mikati, T. V. Tran, and E. Negre, "Experimental Study of Oil Cooled Induction Motor for Hybrid and Electric Vehicles," 2018 XIII International Conference on Electrical Machines (ICEM), 2018, pp. 1195-1200, doi: 10.1109/ICELMACH.2018.8507058.

[18] B. Fahimi, A. Emadi, and R. B. Sepe, "A switched reluctance machine-based starter/alternator for more electric cars," IEEE Transactions on Energy Conversion, vol. 19, no. 1, pp. 116-124, March 2004, doi: 10.1109/TEC.2003.822322.

[19] A. Chiba, K. Kiyota, N. Hoshi, M. Takemoto, and S. Ogasawara, "Development of a Rare-Earth-Free SR Motor with High Torque Density for Hybrid Vehicles," IEEE Transactions on Energy Conversion, vol. 30, no. 1, pp. 175182, March 2015, doi: 10.1109/TEC.2014.2343962.

[20] T. J. E. Miller, "Speed's Electric Motors: An Outline of Some of the Theory in the Speed Software for Electric Machine Design with Problems and Solutions," Magna Physics Publishing, 2006.

[21] P. Xie, R. Ramanathan, G. Vakil, and C. Gerada, "Simplified Analytical Machine Sizing for Surface Mounted Permanent Magnet Machines," 2019 IEEE International Electric Machines \& Drives Conference (IEMDC), 2019, pp. 751-757, doi: 10.1109/IEMDC.2019.8785167.

[22] T. Miller, "SPEED's Electric Motors," University of Glasgow, p. 307, 2002.

[23] Y. Zhang, W. P. Cao, and J. Morrow, "Interior permanent magnet motor parameter and torque ripple analysis for EV traction," 2015 IEEE International Conference on Applied Superconductivity and Electromagnetic Devices (ASEMD), 2015, pp. 386-387, doi: 10.1109/ASEMD.2015.7453625.

[24] Z. Chen and G. Li, "A V Type Permanent Magnet Motor Simulation Analysis and Prototype Test for Electric Vehicle," IEEE Access, vol. 7, pp. 174839-174846, 2019, doi: 10.1109/ACCESS.2019.2957420.

[25] A. Semon, L. Melcescu, O. Craiu, and A. Crăciunescu, "Design Optimization of the Rotor of a V-type Interior Permanent Magnet Synchronous Motor using Response Surface Methodology," 2019 11th International Symposium on Advanced Topics in Electrical Engineering (ATEE), 2019, doi: 10.1109/ATEE.2019.8724856.

[26] Bing Xia, Weizhong Fei, and P. Luk, "Analysis and design of V-spoke ferrite interior permanent magnet machine for traction applications," 2015 6th International Conference on Power Electronics Systems and Applications (PESA), 2015, pp. 1-6, doi: 10.1109/PESA.2015.7398957. 